DOI 10.15593/2224-9354/2017.2.12

УДК 658.51

\author{
Г.А. Гершанок, Д.А. Петров
}

\title{
ФОРМИРОВАНИЕ МЕХАНИЗМА ВЫБОРА КОНЦЕПЦИИ ОРГАНИЗАЦИИ ПРОИЗВОДСТВА НА ОСНОВЕ ХАРАКТЕРИСТИКИ ВЫПУСКАЕМОГО ПРОДУКТА
}

\begin{abstract}
Рассматривается экономическая ситуация Пермского края за период 2011-2016 годы. В Пермском крае наблюдается рост дефицита бюджета, а также снижение индекса промышленного производства. Одной из возможных причин такого положения вещей является неэффективность организации и управления промышленностью региона. Для улучшения состояния экономики края необходимы новые решения проблем инновационного развития промышленности региона. Таким решением является поиск новых и совершенствование существующих подходов по организации производства. Авторами предлагается обобщенная классификация на основе традиционных и современных подходов, классификации свойств и критериев выпускаемого продукта. Предлагается механизм выбора концепции организации производства с помощью двух критериев - принадлежности продукта к определенному классу и полезности продукта с точки зрения производителя и потребителя. На их основе предлагается производить выбор наиболее эффективной для данного продукта системы организации производства по одной из существующих концепций: массовое производство Г. Форда, «бережливое производство», «быстрореагирующее производство» или «активное производство». Согласно выбранной концепции осуществляется преобразование производства с целью обеспечить необходимыми свойствами выпускаемые продукты, при обеспечении оптимальности бизнес-процессов производственной, управленческой и детальной производственной компании в целом.

Эфффективно выбранная концепция организации производства позволяет улучшить производственную деятельность, повысить качество выпускаемого продукта и, как следствие этого, достигнуть ускорения экономического развития предприятий, что положительно сказывается на формировании бюджета и повышает индекс промышленного производства в регионе.

Ключевые слова: экономика региона, экономическое развитие, организация производства, бережливое производство, быстрореагирующее производство, активное производство, классификация продукта, критерии полезности.
\end{abstract}

Пермский край является одним из наиболее экономически развитых регионов России. Основа краевой экономики - высокоразвитый промышленный комплекс, состоящий из таких отраслей, как машиностроение, химия, нефтехимия, металлургия, топливная промышленность, лесная, деревообрабатывающая и целлюлозно-бумажная промышленности.

Однако, основываясь на показателях бюджета [1], можно наблюдать увеличение дефицита в 2016 году более чем на $10 \%$ к уровню 2011 года. Если общий дефицит бюджета на 2011 год составлял 9994 млн руб., то к 2013 году он вырос до 12362 млн руб., что составляет уже около $12 \%$. Примерно такой дефицит бюджета сохраняется и в 2016 году. По прогнозам правительства Пермского края, такой же дефицит останется и на 2017-2018 годы.

(C) Гершанок Г.А., Петров Д.А., 2017

Гершанок Геннадий Александрович - д-р экон. наук, професссор, ФГБОУ ВО «Пермский национальный исследовательский политехнический университет», e-mail: gager2@yandex.ru.

Петров Дмитрий Алексеевич - гл. специалист по системам ППД, Российское представительство компании ЧКОО Нью Лифт Солюшенс Б.В., e-mail: petrovmail88@gmail.com. 
Доходы промышленного комплекса являются одним из основных частей экономики всего края, поэтому во многом проблему роста дефицита бюджета можно связать с торможением темпов развития промышленности. По данным Пермстата, за период с 2010 по 2016 год в целом наблюдается падение индекса промышленного производства (табл. 1) [2], что в свою очередь может говорить о низком уровне производительности труда, неэффективности производства.

Таблица 1

Изменение индекса промышленного производства

\begin{tabular}{|c|c|c|c|c|c|c|c|}
\hline $\begin{array}{c}\text { Наименование } \\
\text { показателя }\end{array}$ & 2010 г. & 2011 г. & 2012 г. & 2013 г. & 2014 г. & 2015 г. & $\begin{array}{c}2016 \text { г. } \\
\text { (январь- } \\
\text { сентябрь) }\end{array}$ \\
\hline $\begin{array}{l}\text { Индекс промышленного } \\
\text { производства, \% }\end{array}$ & 127,2 & 108,9 & 102,6 & 104,7 & 109,5 & 99,4 & 97,9 \\
\hline
\end{tabular}

Таким образом, развитие экономики Пермского края является первостепенной задачей, для решения которой необходимо повышение эффективности промышленного сектора региона. Наш край имеет значительный потенциал для обеспечения эффективного развития промышленных предприятий. Среди основных проблем, тормозящих развитие промышленности, можно выделить такие, как низкий спрос на производимую продукцию, моральный и физический износ основных фондов, технологическая отсталость, высокие издержки на единицу продукции и многие другие моменты. Данные проблемы во многом обусловлены существующим на сегодняшний день неэффективным менеджментом на предприятиях, неэффективной организации производственной деятельности предприятий.

Дальнейшее развитие промышленности и экономики нашего региона должно заключаться в создании новых инновационных и устойчивых производственных структур, способствующих развитию промышленности края. Это требует создания новых комплексных подходов к развитию промышленных предприятий, позволяющих более результативно создавать и использовать имеющийся ресурсный потенциал. Одним из наиболее эффективных процессов, предлагаемых для развития промышленного сектора в сложившихся условиях, является поиск новых и совершенствование существующих подходов к организации производства.

Организация производства является ключевой задачей для любого предприятия, так как она создает предпосылки к решению целого ряда важнейших задач производства: обеспечение высокого уровня качества продукции, оптимальное использование и распределение ресурсов предприятия, рост производительности труда, развитие личности работников и организационной культуры в компании. Существует достаточно большое количество различных концепций организации производства, поэтому отдельной задачей является выбор наиболее эффективной из них.

PNRPU Sociology and Economics Bulletin. 2017. No. 2 
Этот выбор может основываться на различных подходах. Наш подход базируется на двух элементах: обобщенной классификации выпускаемого продукта компании и критериях полезности продукта относительно производителя и потребителя. На этой основе удобно осуществить переход к наиболее эффективной концепции производства для данного продукта. Покажем, как это сделать.

На рис. 1 представлена обобщенная классификация, которую мы произвели на основе как традиционных, так и современных подходов к описанию продукции.

Большинство традииионных подходов разработаны во времена становления промышленности страны и описаны в работах [3-5], где рассматриваются классификации по следующим критериям:

- сфера потребления - описывает место применения продукции с целью удовлетворения какой-либо потребности;

- назначение продукиии - описывает функциональную направленность продукта, а также характеризует способность товаров удовлетворять физиологические и социальные потребности;

- принадлежность к определенному этапу жизненного иикла - характеристика продукта, которая говорит о стадии освоения продукции с позиции подготовленности производства к ее выпуску;

- тип производства - комплексная характеристика технических, организационных и экономических особенностей производства, обусловленная его специализацией, типом и постоянством номенклатуры изделий, а также формой движения изделий по рабочим местам.

Существуют и другие классические подходы, которые здесь мы не представляем.

В качестве современных подходов к классификации продуктов рассматриваются подходы [6], среди которых выделяют такие критерии:

- статус продукта - характеристика продукта, которая говорит о стадии восприятия данного продукта потребителем;

- уровень кастомизации - характеристика продукта по возможности замены отдельных элементов в соответствии с требованиями отдельных заказчиков.

Существуют и другие современные подходы, где рассматриваются менее, с нашей точки зрения, значимые критерии.

Теперь перейдем ко второму элементу - критериям полезности продукта с точки зрения покупателя и производителя.

По мнению производителя, полезность продукта определяется эффективностью вложения ресурсов и ожидаемой прибыли. Для потребителя же полезность - это частичное или полное удовлетворение какой-либо потребности в результате приобретения товара. Однако на разных этапах соотношение полезности продукции для потребителя и производителя разное. 


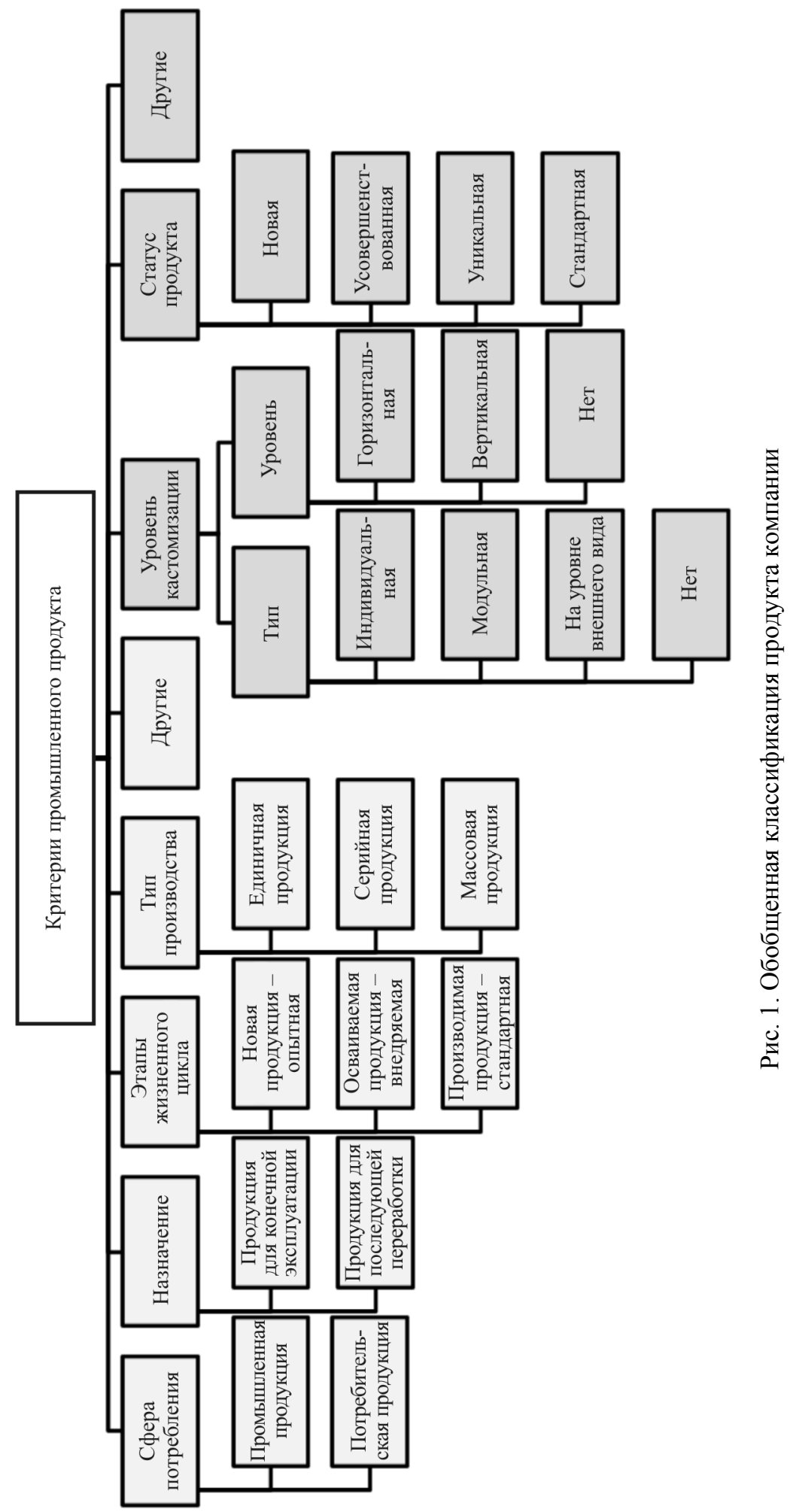

PNRPU Sociology and Economics Bulletin. 2017. No. 2 
В общем случае можно выделить несколько основных критериев полезности продукта для потребителя и производителя (рис. 2).

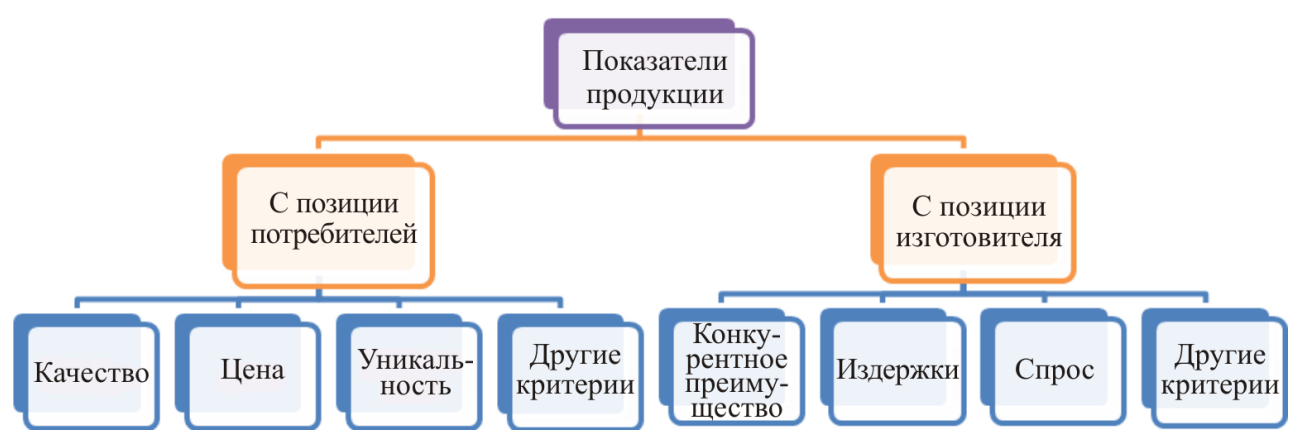

Рис. 2. Основные критерии полезности продукта

Для потребителя в качестве основных критериев мы выделили следующие:

- качество - совокупность свойств продукции, соответствующих предъявляемым требованиям потребителем;

- цена - показатель соотношения выгоды от использования продукта к затратам на его приобретение;

- уникальность - отличительные свойства продукта, от других похожих решений.

Для производителя основными критериями являются:

- конкурентное преимущество - наличие характеристик, выгодно отличающих данный продукт от других аналогичных на рынке;

- издержки - затраты, связанные с производством продукта;

- спрос - востребованность товара со стороны покупателей.

Можно, конечно, выделить еще целый ряд критериев полезности, как с позиции потребителя, так и с позиции производителя, однако мы ограничимся теми, которые считаем основными.

На основе обобщенной классификации продукта и критериях полезности осуществляется переход к той или иной концепции производства под данный продукт [7-12]. В табл. 2 мы приводим основные свойства различных концепций производства, что позволит обоснованно провести этот переход.

Таблица 2

Основные свойства концепций производства

\begin{tabular}{|l|c|c|c|c|}
\hline \multicolumn{1}{|c|}{ Фактор } & Фордизм & $\begin{array}{c}\text { Бережливое } \\
\text { производство }\end{array}$ & $\begin{array}{c}\text { Быстрореагирующее } \\
\text { производство }\end{array}$ & $\begin{array}{c}\text { Активное } \\
\text { производство }\end{array}$ \\
\hline $\begin{array}{l}\text { Стратегический } \\
\text { ориентир }\end{array}$ & Продукт & $\begin{array}{c}\text { Сокращение } \\
\text { издержек }\end{array}$ & $\begin{array}{c}\text { Сокращение } \\
\text { времени }\end{array}$ & $\begin{array}{c}\text { действия в условиях } \\
\text { высокой неопреде- } \\
\text { ленности }\end{array}$ \\
\hline $\begin{array}{l}\text { Тип } \\
\text { производства }\end{array}$ & Массовое & $\begin{array}{l}\text { Крупное серий- } \\
\text { ное и массовое }\end{array}$ & $\begin{array}{c}\text { Серийное } \\
\text { и единичное }\end{array}$ & Единичное \\
\hline
\end{tabular}


Окончание табл. 2

\begin{tabular}{|l|c|c|c|c|}
\hline \multicolumn{1}{|c|}{ Фактор } & Фордизм & $\begin{array}{c}\text { Бережливое } \\
\text { производство }\end{array}$ & $\begin{array}{c}\text { Быстрореагирующее } \\
\text { производство }\end{array}$ & $\begin{array}{c}\text { Активное } \\
\text { производство }\end{array}$ \\
\hline Тип продукта & $\begin{array}{c}\text { Стандартная } \\
\text { продукция }\end{array}$ & $\begin{array}{c}\text { Стандартная } \\
\text { и внедряемая } \\
\text { продукция }\end{array}$ & $\begin{array}{c}\text { Внедряемая } \\
\text { и опытная продукция }\end{array}$ & $\begin{array}{c}\text { Опытная } \\
\text { продукция }\end{array}$ \\
\hline $\begin{array}{l}\text { Уровень } \\
\text { кастомизации }\end{array}$ & Нет & $\begin{array}{c}\text { Низкий - } \\
\text { средний }\end{array}$ & $\begin{array}{c}\text { Средний - } \\
\text { высокий }\end{array}$ & Высокий \\
\hline $\begin{array}{l}\text { Задействованные } \\
\text { ресурсы }\end{array}$ & $100 \%$ & $100 \%$ & $80-90 \%$ & Более $100 \%$ \\
\hline $\begin{array}{l}\text { Инновационный } \\
\text { потенциал }\end{array}$ & Нет & Низкий & Средний & Высокий \\
\hline $\begin{array}{l}\text { Охват } \\
\text { Производство }\end{array}$ & Производство & $\begin{array}{c}\text { Организация } \\
\text { в целом }\end{array}$ & $\begin{array}{c}\text { Организация } \\
\text { в сети - виртуальная }\end{array}$ \\
\hline $\begin{array}{l}\text { Организационная } \\
\text { структура }\end{array}$ & $\begin{array}{c}\text { Отдельные } \\
\text { рабочие места }- \\
\text { конвейер }\end{array}$ & Иерархическая & плоская & Сетевая \\
\hline Формируется & Снизу & Снизу & Сверху & Всеми \\
\hline
\end{tabular}

Первой концепцией, нашедшей общее признание, является парадигма массового производства, рожденная еще в начале двадцатого столетия автомобильной империей Генри Форда. В основе ее лежит несколько ключевых моментов [13]:

1. «Отсутствие страха перед будущим и благоговения перед прошлым. Кто боится будущего, неудач, тот сам ограничивает круг своей деятельности. Неудачи только дают повод более разумно попытаться еще раз. То, что ушло в прошлое, полезно хотя бы потому, что оно открывает новые пути и возможности для прогресса».

2. «Пренебрежение конкуренцией. Тот, кто работает лучше всех, тот и должен работать». При этом он считал, что нельзя наносить вред бизнесу и жизни конкурента, нельзя заменять «господство интеллекта господством силы».

3. «Служение превыше прибыли. Работу на общую пользу необходимо ставить выше выгоды. Без прибыли бизнес не существует. ...Но прибыль не должна быть самоцелью, она должна быть результатом полезной деятельности».

4. «Производить - не значит дешево купить и дорого продать. Этот процесс включает обоюдовыгодное приобретение материалов и превращение его в качественный товар, необходимый покупателю, с минимальными издержками». Махинации будут только препятствовать этому процессу.

Развитие мировой экономики, промышленности привело к появлению конкуренции производственных продуктов не только в одной стране, а в целом мире. Все большее развитие получают крупносерийное и среднесерийное производство, которые стали замещать место массового производства. Появилась конщепиия «бережливого производства» (от англ. lean manufacturing) - 
подход к управлению производственным предприятием на основе стремления исключить все виды потерь, среди которых выделяют восемь основных:

1. Потеря творческого потенциала - потери времени, идей, навыков, возможностей усовершенствования и приобретения опыта из-за невнимательного отношения к сотрудникам, которых вам некогда выслушать.

2. Излишнее производство - производство изделий, на которые не поступало заказа, ведет к избытку запасов и порождает такие потери, как излишек рабочей силы и складских помещений, а также затраты на транспортировку.

3. Задержки - рабочие, которые наблюдают за работой автоматического оборудования, простаивают в ожидании очередной рабочей операции, инструмента, деталей и т.д. или просто сидят без работы из-за отсутствия деталей, задержек в ходе обработки, простоя оборудования и нехватки мощностей.

4. Ненужная транспортировка - перемещение незавершенного производства на большие расстояния, порождающее неэффективность при транспортировке, а также перемещение материалов, деталей и готовых изделий на склад и со склада.

5. Чрезмерные запасы - сырья, незавершенного производства или готовых изделий - увеличивают время выполнения заказа, вызывают моральное старение продукции, ведут к повреждению готовых изделий, затратам на транспортировку и хранение, задержкам и проволочкам. Кроме того, избыток запасов мешает выявлению таких проблем, как несбалансированность производства, задержки поставок, дефекты, простои оборудования и длительная переналадка.

6. Излишняя обработка - ненужные операции при обработке деталей. Неэффективная обработка из-за низкого качества инструмента или непродуманного конструктивного решения, которая влечет за собой лишние движения и ведет к появлению дефектов. Потери, вызванные завышенными требованиями к качеству.

7. Дефекты, которых нужно избегать всеми силами, - производство дефектных деталей и исправление дефектов. Ремонт, переделка, отходы, замена продукции и ее проверка ведут к потере времени и сил.

8. Неналаженные передвижения - все лишние движения, которые приходится делать сотрудникам в процессе работы: поиски того, что нужно, необходимость тянуться за инструментами, деталями и т.П. или заниматься их укладкой. Сюда же относится ходьба.

Однако с 1980-х годов стали играть важную роль скорость создания и выполнения заказа, индивидуальный подход к требованиям заказчика, а также большой спектр возможных опций товара. Предприятия, которые могли предложить покупателям эти полезности, получили явные конкурентные преимущества. Данные изменения послужили причиной появления новых концепций производства. 
Одна из них - концепиия «быстрореагирующего производства» (от англ. Quick response manufacturing, QRM) - подход к управлению производством предприятия на основе стремления быстро выполнять заказ, исключая все временные потери при производстве продукта. Сама концепция базируется на шести основных принципах [11]:

1. Ориентация работников всех подразделений на единую цель - снижение затрат. Причем берется в расчет не только время, непосредственно затрачиваемое на конкретные операции, но и суммарное календарное время, прошедшее от заказа до поставки. Единая цель и единые критерии оценки реального вклада в ее достижение позволяют преодолеть функциональную разобщенность и соединить воедино усилия всего коллектива.

2. Распространение поиска «потерянного времени» с цехового уровня на заводоуправление, маркетинговые, инженерные и логистические службы. В большинстве случаев, основная потеря времени происходит в офисах, а не на производстве.

3. Переход от функциональных цехов к ячейкам с групповой технологией, специализирующимся на производстве семейства того или иного вида изделий или полуфабрикатов с одновременным внедрением командой организации труда.

4. Внедрение на уровне офисных структур многофункциональных ячеек, перекрывающих диапазон ответственности традиционных функциональных подразделений.

5. Переход к использованию системы Pairedcell Overlapping of Cards with Authorization (POLCA) для планирования и контроля движения материалов и полуфабрикатов между производственными ячейками POLCA, в отличие от аналогичной системы KANBAN, используемой в бережливом производстве и рассчитанном на поток, обеспечивает эффективное согласование операций отдельных производственных ячеек.

6. Обеспечение наличие запаса мощностей в размере 10-20 \% по наиболее востребованному оборудованию. Такой резерв жизненно необходим для того, чтобы избежать «пробок» в производственных потоках и избежать временных потерь

Другой концепцией стало «активное производство» (от англ. Agility manufacturing) - подход к управлению производственным предприятием на основе эффективных действий в условиях неопределенности внешней среды. В отличие от бережливого производства и быстрореагирующего, чьи концепции четко сформировались, концепция активного производства находится в стадии формирования и конкретизации, и можно выделить несколько ее особенностей [11]:

1. Сценарная стратегия и постоянная готовность к изменениям.

2. Максимум интеллектуальных и минимум материальных активов. 
3. Гибкость и реконфигурируемость наличного оборудования и помещения.

4. Гибкий персонал: постоянная стержневая группа специалистов - многофункционалов; переменная группа внешних специалистов, работающих на целевой проект; вспомогательный персонал на коротких контактах.

5. Разветвленная сеть партнерских организаций и поставщиков.

6. Организационная структура - плоская, проектная, сетевая, виртуальная.

7. Организация работы - проектно-командная.

В общем виде механизм перехода к концепции производства (рис. 3) представляется нам в виде описания промышленного продукта посредством обобщенной классификации и описания его полезности относительно покупателя и производителя, после чего данное описание сопоставляется со свойствами существующих концепций - для выбора той, которая наиболее оптимально соответствует критериям продукта.

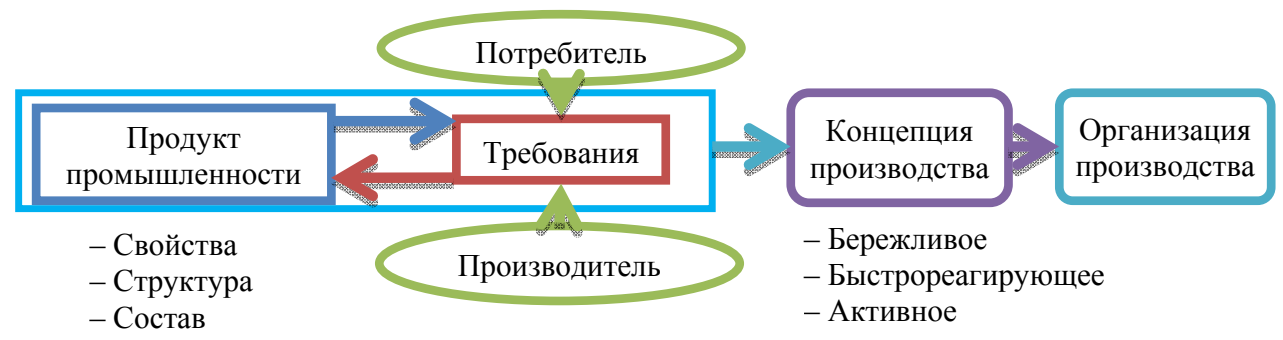

Рис. 3. Схема реализации методики перехода от продукта к концепции производства

В качестве примера рассмотрим продукт промышленности: легковой автомобиль, новая усовершенствованная модель, среднего класса и средней ценовой категории. С позиции обобщенной классификации данный продукт обладает следующими свойствами:

- по сфере потребления - потребительская продукция;

- по назначению - продукция для конечной эксплуатации;

- по этапам жизненного цикла - производимая продукция (стандартная);

- по типу производства - серийная продукция;

- по типу кастомизации - модульная;

- по уровню кастомизации - горизонтальная;

- по статусу продукта - усовершенствованная.

С точки зрения полезности для потребителя: качество - средневысокое, цена - низкая-средняя, наличие уникальности второстепенно. С точки зрения производителя: ожидание высокого спроса, возможность низких издержек; обеспечение конкурентного преимущества планируется за счет усовершенствованных свойств продукта. 
Наиболее подходящей концепцией для данного проекта является бережливое производство, так как именно оно направлено на выпуск крупносерийных партий, сокращение издержек, обеспечение высокого качества продукта, а также позволяет получить необходимый уровень кастомизации продукта.

Концепция производства, которая в полной мере соответствует свойствам продукта и предъявляемым критериям полезности, как потребителя, так и производителя, способна обеспечить высокий уровень качества продукции, оптимальное использование и распределение ресурсов предприятия, рост производительности труда, развитие персонала и организационной культуры компании в целом.

На данный момент среди российских предприятий, использующих современные концепции производств, представлены такие крупные промышленные компании, как «КамАЗ», «Группа ГАЗ», ВСМПО-АВИСМА, «Русал», «ЕвразХолдинг», «Еврохим» и др. [14].

По оценкам экспертов, в результате изменения производственной системы в соответствии с принципами современных концепций производств можно добиться увеличения выпуска продукции на 20-25\%, роста рентабельности производства с 9 до $19 \%$ и роста объемов продаж на 40 \% [14, 15].

Следовательно, механизм выбора эффективной концепции производства начинает играть ключевую роль при создании новых или реорганизации существующих производственных площадок, что обеспечивает рост финансового благополучия предприятий. Следствием этого можно ожидать экономический подъем промышленных регионов России, таких как Пермский край, на территории которого размещены крупные российские промышленные предприятия, требующие нового взгляда на организацию своей деятельности.

\section{Список литературы}

1. Понятный бюджет. Открытый регион. Пермский край [Электронный pecypc]. - URL: http://budget.permkrai.ru/ (дата обращения: 30.10.2016).

2. Территориальный орган Федеральной службы государственной статистики по Пермскому краю [Электронный ресурс]. - URL: http://permstat.gks.ru/ (дата обращения: 30.10 .2016 ).

3. Егорова Т.А. Организация производства на предприятиях машиностроения. - СПб.: Питер, 2004. - 304 с.

4. Новицкий Н.И. Организация производства на предприятиях: учеб.метод. пособие. - М.: Финансы и статистика, 2004. - 392 с.

5. Организация производства на предприятии (фирме): учеб. пособие / под ред. О.И. Волкова, О.В. Девяткина. - М.: ИНФРА-М, 2004. - 448 с. 
6. Минеева Т.А. Принципы моделирования системы организации производства уникальной продукции // Информационные технологии в экономике: теория, модели и методы: сб. науч. тр. - Екатеринбург: Изд-во Урал. гос. экон. ун-та, 2007. - С. 57-66.

7. Вумек Дж., Джонс Д. Бережливое производство. Как избавиться от потерь и добиться процветания вашей компании. - М.: Альпина Паблишер, 2011. $-472 \mathrm{c}$.

8. Тайити Оно. Производственная система Тойоты: уходя от массового производства. - М.: Изд-во ИКСИ, 2012. - 208 с.

9. Лайкер Д.К., Майер Д. Практика ДАО ТОҮОТА. Руководство по внедрению принципов менеджмента ТОҮОТА / пер. с англ. Т. Гутман. - М.: Альпина Бизнес Букс, 2006. - 588 с.

10. Лайкер Д.К., Морган Д. Система разработки продукции в ТОҮОТА. Люди, процессы, технология: пер. с англ. - М.: Альпина Бизнес Букс, 2007. - 440 с.

11. Лузин А.Е., Бабанова Ю.В. Постфордизм - три ключевые парадигмы нового столетия [Электронный ресурс]. - URL: http://qrmrussia.ru/index.php/ publications/22-postfordizm-tri-klyuchevye-proizvodstvennye-paradigmy-novogostoletiya (дата обращения: 19.10.2016).

12. Сури Р. Время - деньги. Конкурентное преимущество быстрореагирующего производства / пер. с англ. В.В. Дедюхина. - М.: БИНОМ. Лаборатория знаний, 2015. $-326 \mathrm{c}$.

13. Форд Г. Моя жизнь, мои достижения / пер. с англ. Н.Н. Рудницкая, Е. Кочерин. - М.: Манн, Иванов и Фербер, 2013. - 304 с.

14. Юркив Н.Н. Бережливость по-русски [Электронный ресурс]. - URL: http://ria-stk.ru/mmq/adetail.php?ID=36369_(дата обращения: 31.10.2016).

15. КамАЗ: Трудно поверить, но такое бывает // Стандарты и качество. 2011. - № 6. - C. 4-6.

\section{References}

1. Poniatnyi biudzhet. Otkrytyi region. Permskii krai [Clear budget. Open region. Perm Krai]. Available at: http://budget.permkrai.ru/ (accessed 30 October 2016).

2. Territorial'nyi organ Federal'noi sluzhby gosudarstvennoi statistiki po Permskomu kraiu [Local office of the Federal State Statistics Service of Perm Krai]. Available at: http://permstat.gks.ru/ (accessed 30 October 2016).

3. Egorova T.A. Organizatsiia proizvodstva na predpriiatiiakh mashinostroeniia [Industrial management at machine-building plants]. Saint-Petersburg, Piter Publ., 2004, 304 p.

4. Novitskii N.I. Organizatsiia proizvodstva na predpriiatiiakh [Industrial management at enterprises]. Moscow, Finansy i statistika Publ., 2004, 392 p.

5. Organizatsiia proizvodstva na predpriiatii (firme) [Corporate industrial management]. Ed. by O.I. Volkov, O.V. Deviatkin. Moscow, INFRA-M Publ., 2004, 448 p. 
6. Mineeva T.A. Printsipy modelirovaniia sistemy organizatsii proizvodstva unikal'noi produktsii [Modeling principles of industrial management system of unique products manufacturing]. Informatsionnye tekhnologii $\mathrm{v}$ ekonomike: teoriia, modeli i metody. Ekaterinburg: Ural. gos. ekon. un-t, 2007, pp. 57-66.

7. Vumek D.P., Dzhons D.T. Berezhlivoe proizvodstvo. Kak izbavit'sia ot poter' i dobit'sia protsvetaniia vashei kompanii [Lean production. How to get rid of losses and achieve prosperity for your company]. Moscow, Al'pina Publisher, 2011, $472 \mathrm{p}$.

8. Ono T. Proizvodstvennaia sistema Toioty: ukhodia ot massovogo proizvodstva [Toyota production system: beyond large-scale production]. Moscow, IKSI Publ., 2012, 208 p.

9. Liker J.K., Meier D. The Toyota way fieldbook: a practical guide for implementing Toyota's 4Ps. The McGraw-Hill Companies, Inc., 2006 [Russ. ed.: Laiker D.K., Maier D. Praktika DAO TOYOTA. Rukovodstvo po vnedreniiu printsipov menedzhmenta TOYOTA. Moscow, Al'pina Biznes Buks Publ., 2006, 588 p.].

10. Liker J.K., Meier D. The Toyota product development system: integrating people, process, and technology. Productivity Press, 2006, 377p. [Russ. ed.: Laiker D.K., Morgan D. Sistema razrabotki produktsii v TOYOTA. Liudi, protsessy, tekhnologiia. Moscow, Al'pina Biznes Buks Publ., 2007, 440 p.].

11. Luzin A.E., Babanova Iu.V. Postfordizm - tri kliuchevye paradigmy novogo stoletiia [Post-Fordism: the three key paradigms of the new century]. Available at: http://qrmrussia.ru/index.php/publications/22-postfordizm-tri-klyuchevye-proizvodstvennye-paradigmy-novogo-stoletiya (accessed 19 October 2016).

12. Suri R. It's About Time. The competitive advantage of quick response manufacturing. Taylor and Francis Group, LLC, 2010 [Russ. ed.: Suri R. Vremia den'gi. Konkurentnoe preimushchestvo bystroreagiruiushchego proizvodstva. Moscow, BINOM. Laboratoriia znanii Publ., 2015, 326 p.].

13. Ford H. My life \& work. Garden City. New York. Doubleday, Page \& Company, 1923 [Russ. ed.: Ford G. Moia zhizn', moi dostizheniia. Moscow, Mann, Ivanov i Ferber Publ., 2013, 304 p.].

14. Iurkiv N.N. Berezhlivost' po-russki [Russian thrift]. Available at: http://ria-stk.ru/mmq/adetail.php?ID=36369 (accessed 31 October 2016).

15. KamAZ: Trudno poverit', no takoe byvaet [It is hard to believe, but it happens]. Standarty i kachestvo, 2011, no. 6, pp. 4-6.

Оригинальность статьи - $77 \%$

Получено 11.01.2017

PNRPU Sociology and Economics Bulletin. 2017. No. 2 


\section{G.A. Gershanok, D.A. Petrov}

\section{FORMATION OF THE MECHANISM OF PRODUCTION ORGANIZATION CONCEPT SELECTION BASED ON THE CHARACTERISTICS OF THE MANUFACTURED PRODUCT}

The article describes the economic situation in Perm Krai between 2011 and 2016. This period saw the growth of budget deficit as well as decrease in industrial production index. One of the possible reasons for this could be organizational inefficiency and poor industrial management of the region. To improve the economic performance of the region, the new solutions for the challenges of regional economic innovative development are to be proposed. One of the decisions lies in searching for the new approaches, as well as working out new strategies of industrial management. The authors of the article offer a general classification of the approaches, based on the traditional and innovative approaches and merchandise hierarchy characteristics. On the basis of this classification the authors suggest the strategy of industrial management concept selection through the criteria of product's belonging to a certain class and its utility from both the customer's and the manufacturer's points of view. Using these strategies allows choosing a more effective system of industrial management, according to one of the existing approaches, including mass production by Henry Ford, lean manufacturing, quick response manufacturing and active manufacturing. On the basis of the selected approach, the company implements production reforms in order to provide the products with the necessary characteristics along with business processes optimization of a manufacturing company management. The paper shows that an effectively selected strategy of industrial management enables to improve industrial activity and the products' quality. This results in the acceleration of companies' economic development, which contributes to a better budget formation and the regional production index advance.

Keywords: region's economy, economic development, industrial management, lean manufacturing, quick response manufacturing, active manufacturing, merchandise hierarchy, measure of utility.

Gennady A. Gershanok - Doctor of Economic Sciences, Professor, Perm State National Research University, e-mail: gager2@yandex.ru.

Dmitry A. Petrov - Chief Expert, New Lift Solutions B.V. (Russian office), e-mail: petrovmail88@gmail.com. 